\title{
Saúde suplementar
}

José Antonio ITURRI ${ }^{1}$

Pode-se afirmar que a natureza, a forma e o grau de intervenção estatal na regulação da oferta e demanda de recursos envolvidos com as redes de cuidados e serviços de saúde mantêm correspondência com a extensão do direito à saúde e com os diversos tipos de sistemas organizados para efetivá-lo. No Brasil, à diferença de outros países que adotaram sistemas universais de saúde (Costa Rica, Canadá, Cuba), “o sistema público convive com um considerável mercado privado de planos e seguros de saúde".

Os planos e seguros de saúde, concretizados por meio de contratos - individualizados ou derivados do contrato de trabalho, na forma de benefícios indiretos - de prestação de serviços/ reembolsos de despesas entre entes privados, representam uma parte das relações estabelecidas no âmbito privado da atenção à saúde. Nesse âmbito deve se diferenciar aquelas relações diretas entre clientes e prestadores (por exemplo, pagamentos diretos dos pacientes aos médicos em consultórios particulares) das modalidades como os planos e seguros, as que envolvem contratos que expressam relações coletivas e se materializam por meio da constituição de fundos constituídos pelas provisões comuns dos clientes.

Esta característica afasta os planos e seguros de saúde das definições simplificadoras do termo "mercado": De forma sintética, pode se considerar que o conceito tradicional de mercado ajustase melhor às relações diretas entre consumidores e prestadores de serviços. Já no caso dos planos e seguros de saúde, a existência de fundos que são constituídos pelas prestações dos muitos clientes e utilizadas pelos clientes individuais de forma heterogênea (a depender da situação de saúde) imprimem neles uma racionalidade essencialmente coletiva, inclusive nos planos e seguros denominados individuais/familiares.

Pode-se acrescentar que, quando aplica uma definição estrita de "mercado" apenas como lugar de troca entre compradores livres e informados e vendedores individuais de serviços, constata-se que essa definição "praticamente inexiste na saúde" porque numerosas instituições de ensino e corporações profissionais, ao lado de órgãos governamentais, normatizam, regulam e autorizam o trabalho dos profissionais e as práticas assistenciais; "os produtos da saúde não podem ser produzidos, nem vendidos ou comprados por qualquer cidadão”. Consequentemente, é necessária a intermediação institucional para regular a oferta dos prestadores de serviços e os custos dos procedimentos.

1 Doutor em Saúde Coletiva pela Universidade do Estado do Rio de Janeiro. Professor Adjunto da Universidade de Brasília / Faculdade de Ceilândia (FCE/UnB) e Coordenador Adjunto do Curso de Saúde Coletiva/FCE/UnB. Contato: iturri@unb.br 


\section{O MERCADO DE PLANOS E SEGUROS DE SAÚDE}

As informações de abrangência nacional sobre a cobertura de planos e seguros privados no Brasil são basicamente estimativas. A maioria provém da Pesquisa Nacional por Amostra de Domicílios (PNAD), realizada pelo Instituto Brasileiro de Geografia e Estatística (IBGE), que desde o final dos anos 90 inclui perguntas sobre coberturas desse mercado. A estimativa da proporção da população coberta por planos ou seguros de saúde (incluindo os produtos para militares e funcionários públicos) era de 24,5\% em 1998.

Esse resultado foi praticamente o mesmo de 2008: 25,9\%. Contudo, para compreender a magnitude do setor não deve-se observar apenas o número de pessoas cobertas.

Quando se leva em consideração outras dimensão, como o faturamento das empresas, os recursos assistenciais mobilizados e a quantidade e diversidade de empresas envolvidas "verificase que a esfera de influência do mercado de planos e seguros privados de saúde é muito superior à da órbita da sua cobertura populacional". Com dados até 2009, temos que pelo menos $60 \%$ dos hospitais brasileiros, $65 \%$ dos médicos e mais de $90 \%$ das unidades isoladas de diagnóstico e terapia estão vinculadas parcial ou totalmente a planos e seguros privados.

A despeito de as coberturas populacionais pro planos e seguros terem se mantido quase inalteradas desde o final dos anos 90, o mercado brasileiro de planos e seguros privados cresceu, seja em número absoluto de cliente ou no incremento do seu faturamento, em especial entre 2004 e 2009.

A desproporção entre uma proporção de clientes de cerca de $25 \%$ da população e a oferta potencial, por parte dos planos e seguros privados de saúde, de mais de $50 \%$ dos recursos e serviços assistenciais é marca distintiva do sistema de saúde brasileiro. Esse aparente desequilíbrio se sustenta pela duplicidade de uso dos mesmos recursos tanto por demandantes vinculados aos planos quanto por usuários não vinculados.

A duplicidade de uso dos recursos viabiliza-se pela discriminação de portas de entrada diferenciadas - em especial, hospitais que atendem usuários de ambos vínculos - bem como pelos múltiplos empregos dos profissionais de saúde, especialmente médicos, contratados tanto nos serviços públicos quanto nos privados.

Existem duas situações notórias em relação à duplicidade de uso da oferta de recursos. Pelo lado dos serviços privados, tem-se que as unidades de apoio diagnóstico e terapêutico se voltam principalmente para atender clientes de planos e seguros privados e, em menor proporção, clientes particulares. Pelo lado do setor público, especificamente do financiamento público, verifica-se que a rede de hemodiálise - composta por serviços privados, quase exclusivamente financiados por recursos públicos - atende ambas clientelas. Ainda, verifica-se que outros serviços públicos - os de caráter preventivo, como vacinação, e, em especial, os que concentram suas atividades na // Tempus, actas de saúde colet, Brasília, 8(2), 91-95, jun, 2014.

ISSN 1982-8829 
realização de procedimentos de alta complexidade e custo, como transplantes, cirurgias cardíacas e terapia de neoplasias- atendem ambas clientelas. Essa duplicidade de uso dos recursos disponíveis implica em um racionamento adicional aos segmentos de população não vinculados aos planos e seguros privados, visto que o atendimento a esse segmento será submetido aos escrutínio dos critérios de ordem de chegada, gravidade das condições clínicas, existências de vagas. Já para os clientes do mercado privado - que obtém acesso mediante solicitação dos procedimentos às empresas que os comercializam - é menos provável a falta de recursos de atenção.

A segmentação do sistema de saúde brasileiro leva a que a estimativa de despesas - excluindo os gastos privados diretos com assistência e medicamentos - por habitante do sistema público fosse - em 2008 - de R 560 e as despesas por cliente de planos privados alcançavam R 1.680 .

O conjunto de dados sobre os recursos mobilizados por esse mercado ajuda a compreender, por um lado, sua vitalidade financeira e capacidade de atendimento aos segmentos inseridos no mercado formal de trabalho ou situados nas faixas de maior renda e, por outro lado, a influência importante que ele exerce sobre os índices de preços ao consumidor quando se considera que, com frequência, os aumentos dos valores das prestações de planos e seguros estão acima dos índices gerais de inflação e reajuste dos salários.

Existem quatro principais modalidades de empresas de saúde suplementar:

1. Medicina de Grupo: A gestão dos planos é feita por uma empresa privada criada historicamente por proprietários ou sócios de hospitais. Os serviços podem ser prestados por unidades próprias, em que os profissionais de saúde são empregados da empresa de medicina de grupo, ou através de unidades credenciadas por esta. As operadoras de medicina de grupo têm como clientes indivíduos e empresas.

2. Seguro de Saúde: Trabalham sob a lógica do reembolso das despesas com serviços. Seus clientes são indivíduos e empresas. O valor do reembolso tem teto predefinido. Nesta modalidade mais de $90 \%$ das despesas médico-hospitalares são pagas diretamente à rede, existindo centrais de atendimento e autorização, entre outros mecanismos de contenção de custos. A seguradora não pode, por lei, fazer prestação direta de serviços.

3. Cooperativas de Trabalho Médico: Formadas por profissionais médicos vinculados às cooperativas, denominados cooperados. São classificadas em singulares, central ou federação e confederação. As cooperativas singulares têm área de atuação em municípios, sendo que algumas possuem hospitais próprios, onde os médicos são cooperados. Sua clientela é composta por pessoas físicas e jurídicas.

4. Autogestão: os serviços de assistência à saúde são voltados para os empregados de empresas e muitas vezes seus familiares, podendo ser organizados diretamente pela empresa $(\mathrm{RH})$ ou outra organização que institui e administra, pelos próprios empregados, por meio de caixas de assistência, 
associações, sindicados, fundações, sem finalidade lucrativa.

Os dados sobre o número e porte de empresas especializadas na oferta de planos e seguros privados no Brasil mostram que em 2011 haviam 1.187 empresas (excluindo as que se dedicam exclusivamente aos planos odontológicos). Esse é um número elevado em relação à população de clientes, quando comparado com outros países; por exemplo, nos Estados Unidos, em 2007, tinham-se 1.300 empresas cobrindo cerca de 200 milhões de clientes; "no Chile e na Colômbia, em 2006, o número reduzido de empresas (...) (menos de vinte) tampouco condiz com o padrão brasileiro".

Em 2011, oito empresas administravam contratos de mais de 13 milhões de clientes, apontando a concentração desse mercado, dado que coexiste com o fato de $72 \%$ do total das empresas possuírem menos de 20 mil contratos, indicando a multiplicação de planos privados locais.

\section{A REGULAÇÃO DO SETOR DE SAÚDE SUPLEMENTAR}

Desde o final dos anos 80 o setor de planos e seguros privados aumenta sua importância e visibilidade, nem só pelo seu crescimento, mas pela ocorrência de casos de negação de cobertura a pacientes HIV positivos e a idosos, de não atendimento de gestantes de alto risco, os conflitos com entidades médicas pela interferência das empresas na autonomia profissional e outras ocorrências que integraram uma coalizão de interesses a favor da regulamentação do setor.

Somente em 1998 foi promulgada a Lei 9656/98 que dispõe sobre a regulamentação das empresas desse mercado e, em 2000, a Lei 9961 que criou a Agência Nacional de Saúde Suplementar (ANS), constituída como autarquia sob o regime especial, vinculada ao Ministério da Saúde, prazo de duração indeterminado e atuação em todo o território nacional, como órgão de regulação, normatização, controle e fiscalização das atividades que garantam a assistência suplementar à saúde. A ANS tem como instância máxima de decisão a Diretoria Colegiada, contando também com a Procuradoria, Corregedoria e Ouvidoria, além de unidades especializadas, incumbidas de diferentes funções.

De acordo com o Conselho Nacional de Secretários de Saúde (CONASS), a ANS vem desenvolvendo e aprimorando inúmeros mecanismos voltados para a geração e a difusão de informações relativas ao setor de saúde suplementar, com a finalidade de estabelecer canais de comunicação com os atores do mercado. A constituição de câmaras técnicas e a prática de consultas públicas acerca dos mais variados temas têm representado importantes instrumentos para aprofun damento e validação de questões relacionadas à regulamentação.

Ainda de acordo com o CONASS, das ligações recebidas em 2008 pelo Disque ANS 43, 9\% diziam respeito a 7.191 reclamações e, no ano de 2009, as reclamações aumentaram para $12 \%$ das consultas recebidas pela Agência, atingindo 12.861, elevando, portanto, o número de reclamações de planos de saúde, entre 2008 e 2009, em 78,85\%.2 No Relatório Anual 2012 da Ouvidoria ANS // Tempus, actas de saúde colet, Brasília, 8(2), 91-95, jun, 2014.

ISSN 1982-8829 
constata-se "número crescente de reclamações recebidas no órgão em relação às operadoras de planos de saúde".

Essas informações problematizam a efetividade da regulação pública exercida no setor a que pode ser melhor compreendida à luz da idéia de "complementaridade público - privado que caracteriza o híbrido institucional do sistema de saúde brasileiro"2. Essa complementaridade está marcada por ambigüidades na relação entre os setores sociais que se relacionam diretamente com os planos e seguros privados:

"Para os clientes, as vantagens das coberturas dos planos de saúde superam as insatisfações com os preços e as barreiras ao acesso aos serviços de saúde (...) os profissionais, ainda que manifestem desacordos com os valores de remuneração e intervenções nas condutas [clínicas] não prescindem dos credenciamentos que os vinculam [com as empresas]" e ainda pode-se afirmar que "as parcelas da sociedade brasileira mais aquinhoadas dispõem de acesso a ambos os subsistemas"2.

Para Lígia Bahia, em curto prazo, as perspectivas de transformação da mencionada complementaridade público-privada, "parecem remotas". Ela situa só no longo prazo a probabilidade de desenvolver novos paradigmas assistenciais que modifiquem as características dessa relação público-privado numa visão sistêmica orientada pela solidariedade.

$\mathrm{Na}$ Semana de Acolhimento de novos servidores do MS, caberia recolocar essa perspectiva pouco otimista, problematizando-a do ponto de vista da gestão federal e de seus instrumentos de regulação.

\section{REFERÊNCIAS BIBLIOGRÁFICAS}

1. BAHIA L, SCHEFFER M. Planos e Seguros Privados de Saúde. In: GIOVANELLA L. et al (org.). Políticas e Sistema de Saúde de Saúde no Brasil. 2 ed.rev e amp. Rio de Janeiro: Editora FIOCRUZ, 2012.

2. BRASIL. Conselho Nacional de Secretários de Saúde. Saúde Suplementar/Conselho Nacional de Secretários de Saúde. Coleção Para Entender a Gestão do SUS 2011, 12 Saúde Suplementar Brasília : CONASS, 2011.

3. ANS - Agência Nacional de Saúde Suplementar. Ouvidoria ANS - Relatório Anual 2012. Brasília. 2012.

Artigo apresentado em 09/12/13

Artigo aprovado em 11/01/14

Artigo publicado no sistema: 22/03/14 